\title{
Exame morfológico da telenovela Avenida Brasil
}

\author{
Luís Enrique Cazani Júnior \\ Doutorando, mestre e graduado \\ em Comunicação pela Faculdade \\ de Arquitetura, Artes e Comunicação \\ da Universidade Estadual Paulista \\ "Júlio de Mesquita Filho". \\ E-mail: cazani@faac.unesp.br
}

Resumo: Esta comunicação apresenta o exame morfológico da primeira fase de Avenida Brasil (2012), telenovela escrita por João Emanuel Carneiro e veiculada às $21 \mathrm{~h}$ pela Rede Globo de Televisão. O protocolo metodológico propõe um olhar diferenciado sobre o objeto, levantando sua constituição, os regimentos e os relacionamentos, identificando, distinguindo e explicando seus componentes por meio de 31 funções cunhadas por Propp.

Palavras-chave: Telenovela; Morfologia; Funções; Avenida Brasil; Propp.

\section{Morphological examination of the soap opera Avenida Brasil}

Abstract: This paper presents the morphological examination of the first season of Avenida Brasil (2012), soap opera written by João Emanuel Carneiro and displayed on Globo Television in the primetime broadcaster. The methodological protocol proposes a different view on the subject, raising your constitution, the regiments and the relationships, identifying, distinguishing and explaining your components through 31 functions by Propp.

Keywords: Soap Opera; Morphology; Functions; Avenida Brasil; Propp. 
${ }^{1}$ Vladimir Propp foi um estudioso russo que reconheceu em um conjunto de narrativas folclóricas a repetição de ações, denominando-as como funções das personagens.

\footnotetext{
${ }^{2}$ Também conhecido como tableau, recurso proveniente do melodrama francês.
}

\section{Introdução}

Avenida Brasil (2012), telenovela de João Emanuel Carneiro, estabelece-se a partir da ascensão, do acidente, da fuga e da culpa de um personagem central. Após conquistar o Campeonato Carioca, Jorge Tufão atropela e mata Genésio, evento que encerra o primeiro capítulo. Um clamor por Carmen Lúcia são as últimas palavras do morto. Na exibição do dia seguinte, Tufão aciona o resgate, mas parte logo em seguida, deixando o moribundo para trás. Se o jogador tivesse permanecido no local e assumido as consequências do acidente, não se teria tido uma das melhores telenovelas da atualidade. O remorso moveu o jogador para os braços da vilania e deu parâmetros para a ação do protagonismo. Com base nessa premissa, procurouse levantar a organização da história, utilizando as funções das personagens de $\operatorname{Propp}^{1}$ (2010): "afastamento, proibição, transgressão, interrogatório, informação, ardilosidade, cumplicidade, dano, mediação, início da reação, partida, primeira função do doador, reação do herói, recepção do meio mágico, deslocamento, combate, marca, vitória, reparação do dano, regresso, perseguição, salvamento, chegada incógnita, pretensões infundadas, tarefa difícil, realização, reconhecimento, desmascaramento, transfiguração, castigo e casamento".

Personagens memoráveis passaram por Avenida Brasil (2012). Entretanto nenhuma exerceu tamanha fascinação quanto Carmen Lúcia, a Carminha. Na primeira fase, composta pelos sete primeiros capítulos, que constituem o corpus de análise, ela planeja um golpe contra Genésio, seu marido. Após desmascará-la, ele morre atropelado a caminho da delegacia em um acidente que envolve Jorge Tufão. Ao aproximar-se da vilã para ajudá-la, levado pela culpa, Tufão é seduzido e casa-se com ela. Ocultando sua existência e tramando contra o jogador, Carminha abandona Rita, sua enteada, em um lixão. Adotada, a menina parte para a Argentina, prometendo regressar para vingar-se da madrasta, em nome de seu pai. Na linha secundária, Cadinho é amigo de infância do jogador e mantém, secretamente, dois casamentos, um com Noêmia e outro com Verônica. Ao conhecer Alexia, ele tenta estabelecer uma terceira família.

Com o famoso verso "Oi, oi, oi", que integra a releitura de Robson Moura e Lino Krizz da canção Danza Kuduro, a vinheta de abertura da novela entusiasmava o público. O freeze ${ }^{2}$ no encerramento tornou-se a marca dos ganchos narrativos e um hit nas redes sociais. $\mathrm{O}$ efeito criado com as luzes captadas na avenida homônima demarcava as transformações no enredo. A celeridade conquistada por meio da completude imediata de ações e de estágios da história, o acúmulo de acontecimentos, o emprego de recursos tensivos consagrados pela dramaturgia e a distensão com a comicidade contribuíram para o sucesso. A visualidade cinematográfica da obra, com utilização de planos abertos e iluminação carregada, produziram efeitos de sentido diferenciados para um modelo clássico.

A versatilidade de João Emanuel Carneiro na arte de elaborar histórias, seja para o cinema, para revistas em quadrinhos ou para a televisão, marca sua trajetória profissional, favorecendo que expedientes de linguagem se estendam de uma mídia para outra. De suas telenovelas, Da cor do pecado (2004) e Cobras \& Lagartos (2006) foram recordistas de audiência no horário das $19 \mathrm{~h}$. Ao estrear às $21 \mathrm{~h}$ com A favorita (2008), não conquistou a crítica de forma unânime. A ausência do reconhecimento prévio de quem era a vilã quebrou um paradigma que marcava uma das matrizes de linguagem da telenovela: o melodrama clássico. No primeiro momento, coube ao público ler o subtexto da trama e apostar em que esferas as personagens Flora e Donatela se situavam. Se, nessa telenovela, o público era movido pela dubiedade, em Avenida Brasil (2012) o caráter das personagens foi previamente apresentado. Contudo as esferas do antagonismo e do protagonismo acabaram interpolando-se com a heroína vingadora e a vilã carismática. Em A regra do jogo (2015), obra mais recente, o autor voltou a dividir opiniões sobre as personagens transgressoras.

Licenciada para exibição em 132 países $^{3}$, Avenida Brasil (2012) tornou-se, dessa forma, marco na história da teledramaturgia brasileira por inovações que atingiram tanto a narrativa quanto a linguagem audiovisual, que conferiram caráter único a essa produção.
${ }^{3}$ Dados divulgados pelo UOL em 18 de junho de 2016. Disponível em: <https://bit.ly/2Gqw2m2>. 


\section{Análise morfológica de Avenida Brasil}

A análise morfológica propõe um olhar diferenciado sobre o objeto. Ao examinar um arranjo, procura-se levantar a constituição, os regimentos e os relacionamentos existentes, identificando, distinguindo e explicando seus componentes. Nos estudos acerca do folclore russo, Vladimir Propp é comumente reconhecido pela sua morfologia do conto de magia.

Do ponto de vista morfológico podemos chamar de conto de magia todo desenvolvimento narrativo que, partindo de um dano (A) ou uma carência (a) e passando por funções intermediárias, termina com o casamento $\left(\mathrm{W}^{0}\right)$ ou outras funções utilizadas como desenlace. A função final pode ser a recompensa (F), obtenção do objeto procurado ou, de modo geral, a reparação do dano (K), o salvamento da perseguição (Rs) etc. A este desenvolvimento damos o nome de sequência. A cada novo dano ou prejuízo, a cada nova carência, origina-se uma nova sequência. (PROPP, 2010: 90)

O folclorista empreendeu esforços para entender esse tipo de narrativa, considerando as pontuações de Nicolai Yakovlevich Marr sobre a língua e a sociedade, a classificação de contos de magia de Antti Aarne e de Stith Thompson, além do corpus reunido por Aleksandr Nikoláevitch Afanássiev. Destaca-se que sua pesquisa compartilha dos mesmos objetivos da teoria formalista russa, sendo inserida nessa corrente.

No estudo comparativo entre cem contos, Propp (2010) levantou seus acontecimentos em comum, atentando para seu papel na progressão da história. Ao indicar a relação entre as ações na constituição da totalidade de sentido, o folclorista vislumbrou suas significações para, então, descrevê-las. Com base nesse pressuposto, foi estabelecida uma estrutura composta por funções. Segundo Propp (Ibid.: 22), "por função compreende-se o procedimento de um personagem, definido do ponto de vista de sua importância para o desenrolar da ação".

Os estudos proppianos estabelecem alguns postulados: a função deve ser compreendida como unidade básica; para sua definição é necessário situá-la na história e suplantar a atuação da personagem; numericamente, decompõe-se o gênero em 31 funções e acrescenta-se a elas a exposição inaugural; e, por fim, as funções são vislumbradas em uma linha única e invariável, ainda que haja supressão de ações. O primeiro olhar do autor foi sobre eventos no corpus. Em seguida, Propp analisou a execução e estabeleceu esferas de ação. $O$ cânone proposto reúne momentos iterativos e descarta os singulares.

Em resposta à crítica realizada por Claude Lévi-Strauss, Propp (Ibid.) pondera sobre a aplicação de seu método em outros gêneros literários.

${ }^{4}$ Embora seja uma teoria importante para se realizar a segmentação em alguns tipos de narrativas, ela se mostra deficiente, entre outras coisas, como modelo explicativo das relações entre a sociedade (e os seus discursos) e as narrativas ali produzidas. Enfim, ela não dá conta de uma análise, por assim dizer, mais dialética. São limitações do método: o número baixo de funções das personagens, as definições abstratas, a invariabilidade questionável da sequência de funções e a supressão da personagem na aplicação. Ainda assim, foi capaz de motivar estudos como o percurso gerativo de sentido de Algirdas Greimas.
É bem provável que o método de análise das narrativas segundo as funções dos personagens se revele útil também para os gêneros narrativos não só do folclore, mas também da literatura. Todavia, os métodos propostos neste volume antes do aparecimento do estruturalismo, bem como os métodos dos estruturalistas, que almejam o estudo do objetivo e exato da literatura, possuem também os seus limites de aplicação. Eles são possíveis e fecundos no caso de uma repetição em ampla escala. É o que ocorre na língua, é o que ocorre no folclore. (Ibid.: 256)

Partindo desse pressuposto, o autor estende a utilização desse protocolo metodológico para outros tipos de enunciados, desde que se considere suas particularidades e limitações ${ }^{4}$, expostas em Morfologia do conto maravilhoso.

\section{Descrição das ações}

Denomina-se como definição reduzida a notação empregada nos estudos proppianos para identificar acontecimentos extraídos das histórias analisadas, elaborada pelo 
folclorista com a substantivação do verbo da ação. O Quadro 1 apresenta as funções segundo esse viés, distribuídas na tríade transição, ação e reação, e descritas, em seguida, de acordo com Propp (Ibid.). As tonalidades revelam os efeitos de sentido desprendidos dos acontecimentos: o tom esverdeado demonstra os deslocamentos; o amarelado estabelece o estado de atenção para mudanças; e, por fim, a cor avermelhada apresenta a concretização.

\begin{tabular}{|c|c|c|}
\hline Transição & Ação & Reação \\
\hline \multirow[t]{5}{*}{ Afastamento (I) } & Proibição (II) & Transgressão (III) \\
\hline & Interrogatório (IV) & Informação (V) \\
\hline & Ardil (VI) & Cumplicidade (VII) \\
\hline & Dano (VIII) & \\
\hline & Mediação (IX) & Início da reação (X) \\
\hline \multirow[t]{2}{*}{ Partida (XI) } & $\begin{array}{c}\text { Primeira função do } \\
\text { doador (XII) }\end{array}$ & Reação do herói (XIII) \\
\hline & $\begin{array}{l}\text { Recepção do meio } \\
\text { mágico (XIV) }\end{array}$ & \\
\hline \multirow[t]{3}{*}{ Deslocamento (XV) } & Combate (XVI) & Marca (XVII) \\
\hline & & Vitória (XVIII) \\
\hline & & Reparação do dano (XIX) \\
\hline Regresso (XX) & Perseguição (XXI) & Salvamento (XXII) \\
\hline \multirow{6}{*}{$\begin{array}{l}\text { Chegada incógnita } \\
\qquad(X X I I I)\end{array}$} & Pretensões infundadas (XXIV) & \\
\hline & Tarefa difícil (XXV) & Realização (XXVI) \\
\hline & Reconhecimento (XXVII) & Desmascaramento \\
\hline & & (XXVIII) \\
\hline & & $\begin{array}{l}\text { ransinguraçao }(X X \mid X) \\
\text { Castigo }(X X X)\end{array}$ \\
\hline & & \\
\hline
\end{tabular}

Quadro 1: As ações, reações e transições das personagens no conto maravilhoso Fonte: Cazani Júnior (2016)

\section{Situação inicial}

A apresentação das personagens, do tempo e do espaço situa o receptor no contexto da história. Mensura-se, portanto, o seu estado nessa breve exposição inaugural: o antagonista encontra-se comedido em um cenário sereno e regulado. São indicados, então, os fios que tecerão a trama e a caracterização das unidades básicas da narrativa. Dessa forma, o momento não é considerado como uma função da personagem.

Na leitura de Propp (2010: 28), "a situação inicial dá a descrição de um bemestar particular, por vezes sublinhado propositalmente", e "este bem-estar serve, evidentemente, de fundo contrastante para a adversidade que virá a seguir". O florescimento do conflito é desencadeado pelas funções de preparação, e a sua superação torna-se o objetivo do herói.

\section{Funções de preparação (I a VII)}

As funções de preparação instauram o conflito. O processo é iniciado com a ausência (I), temporária ou permanente, de integrante do núcleo familiar. O distanciamento, seja do supervisor ou supervisionado, fragiliza as relações e permite que o antagonismo se manifeste. Ainda neste trecho, ao protagonista é apresentada uma norma (II), negando seu direito sobre a execução de uma atividade ou estabelecendo a sua realização. A infração desse contrato (III) mobilizará o antagonismo. Indagações (IV) são feitas objetivando obter dados relevantes ou esclarecimentos (V). Há, ainda, operações de manipulação (VI), com ocultação de identidade e uso de magia, cujo êxito instituirá a conivência (VII) entre os envolvidos. 


\section{Conflito ou intriga (VIII a XI)}

Os efeitos da infração são intensificados e irrompem na história como conflito (VIII). Sequestros, roubos, destruições, assassinatos, expulsões e lesões são os delitos mais comuns. Quando o conflito emerge, modifica-se a premissa da história e adequa-se os seres às novas condições. Nas suas pesquisas, Propp apresenta, também, o conflito íntimo que provém da interioridade do ser: o "conto começa por uma certa situação de carência ou penúria o que leva a uma procura, análoga à procura no caso dano-agressão" (Ibid.: 34 , grifos originais). O anúncio (IX) da transformação estabelece uma conduta prévia a ser exercida pelo protagonista para a reabilitação da harmonia, levando-o a reagir (X). Como resultado, o protagonista deixa a sua morada e parte (XI), por iniciativa própria, quando solicitado (herói) ou expulso (vítima).

\section{Auxiliar mágico (XII a XIV)}

O primeiro passo para subtrair o antagonismo da história ocorre na conquista do bem ou atributo capaz de superá-lo. Duas ações possibilitam o recebimento deste: o protagonista passa por uma provação (XII), cujo resultado (XII) é avaliado e recompensado (XIV) pelo doador. Dessa forma, o protagonismo se fortalece. $\mathrm{O}$ trecho não sinaliza um duelo com o antagonista.

\section{Confronto $(X V$ a $X I X)$}

Após o recebimento do auxiliar mágico, o protagonista busca o vilão, seja para puni-lo ou recuperar algo que foi por ele apropriado. Geralmente, há o caminho a ser percorrido até o local onde ele se encontra (XV). No embate (XVI), o protagonista é ferido (XVII) ou recebe o objeto que será utilizado na sua identificação posteriormente. Com o triunfo do protagonista (XVIII), o conflito é superado (XIX).

\section{Novas adversidades ( $X X$ a $X X V I)$}

Segundo o folclorista russo, o conto maravilhoso pode apresentar novas ações após o êxito do protagonista, prolongando os efeitos de sentido da história. O protagonista retorna a sua morada $(X X)$ e, durante esse trânsito, é alvo de uma caçada do antagonista, que tenta recuperar seu domínio (XXI). O protagonista se salva (XXII) e se esconde (XXIII). Enquanto isso, uma outra personagem pode apropriar-se de seus feitos (XXIV). Por fim, o protagonista necessita superar um novo desafio (XXV), realizando-o (XXVI).

\section{Desfecho (XXVII a XXI)}

O desfecho institui a resolução da história e a estabilização dos estados das personagens. O protagonista é identificado (XXVII) por meio do objeto, ferimento ou realização do desafio proposto. $O$ sentido da função reconhecimento aproxima-se do conceito homônimo postulado por Aristóteles acerca do enredo da tragédia grega. A ascensão do herói (XXVIII) institui mudanças na sua condição de vida ou fisionomia, e, consequentemente, promove a queda (XXIX) e a punição do antagonista (XXX). Encerra-se a história com o matrimônio (XXXI).

\section{Exemplo}

A obra de Propp (Ibid.) apresenta alguns contos de magia sob a luz das funções das personagens. Como forma de vislumbrar o método, apresenta-se uma dessas análises:

O czar e suas três filhas (situação inicial $-\alpha$ ). As filhas saem para passear (afastamento dos mais novos $-\beta^{3}$ ), demoram-se no jardim (rudimento de proibição transgredida $-\delta^{1}$ ). Um dragão as rapta (nó da intriga $-A^{1}$ ). O czar pede ajuda $\left(\right.$ apelo - $\mathrm{B}^{1)}$. Três heróis partem para procurá-las $(\mathrm{C} \uparrow)$. Três combates contra o dragão e vitória $\left(\mathrm{H}^{1}-\mathrm{J}^{1}\right)$, libertação das jovens (reparação do dano $-\mathrm{K}^{4}$ ). Regresso $(\downarrow)$. Recompensa $\left(w^{3}\right)$. (PROPP, 2010: 129) 
Nota-se que esse conto possui apenas uma sequência e não contém todas as funções propostas. A numeração que segue o símbolo da função é uma marca de sua variação.

\section{Sequência fundamental ou linha narrativa}

Após estabelecer a linha fundamental da narrativa constituída das funções das personagens, Propp (Ibid.) tece algumas considerações sobre deslocamento, emparelhamento, assimilação, dupla significação e triplicação. O paradigma proppiano estabelece um eixo de ações único e invariável, ou seja, existe apenas uma possibilidade de combinação dos eventos. Contudo, são indicados por Propp (Ibid.) casos de supressões e deslocamento de eventos que diversificam essa proposta. Há ainda a disposição das funções em pares comum ao método.

\begin{tabular}{|c|c|c|c|c|c|c|c|c|c|c|c|c|c|c|c|c|c|c|c|c|c|c|c|c|c|c|c|c|c|c|c|}
\hline \multirow{2}{*}{$\alpha$} & \multicolumn{7}{|c|}{$I-V I I$} & \multicolumn{4}{|c|}{ VIII - XI } & \multicolumn{3}{|c|}{ XII - XIV } & \multicolumn{5}{|c|}{$X V-X I X$} & \multicolumn{7}{|c|}{$X X-X X V I$} & \multicolumn{5}{|c|}{ XXVII - XXXI } \\
\hline & $\beta$ & $y$ & $\delta$ & $\varepsilon$ & $\zeta$ & $\eta$ & $\theta$ & $\mathrm{A}$ & $B$ & C & $\uparrow$ & $\mathrm{D}$ & $\mathrm{E}$ & $\mathrm{F}$ & $\mathrm{G}$ & $\mathrm{H}$ & 1 & $\mathrm{~J}$ & K & $\downarrow$ & $\mathrm{Pr}$ & Rs & 0 & $\mathrm{~L}$ & $M$ & $N$ & c & Ex & $T$ & & $\mathrm{~W}$ \\
\hline
\end{tabular}

Quadro 2: Sequência fundamental ou linha narrativa.

Fonte: Propp (Ibid.)

A assimilação atribui o mesmo sentido para ações diferentes. O evento pode enquadrar funções similares, utilizando a lógica para sua distinção. Já a dupla significação consiste na classificação do evento em mais funções. Por fim, triplicação amplifica o efeito do segmento com a instauração de outro correspondente. Os estudos proppianos distribuem os eventos de acordo com quem os executa. Os papéis desempenhados não são fixos: admite-se supressão, acumulação e divisão das esferas.

\begin{tabular}{|c|l|}
\hline Antagonista & Dano (VIII), combate (XVI) e perseguição (XXI). \\
\hline Falso-herói & Partida (XI), reação do herói (XIII) e pretensões infundadas (XXIV). \\
\hline Princesa e rei & $\begin{array}{l}\text { Tarefa difícil (XXV), marca (XVII), desmascaramento (XXVIII), } \\
\text { reconhecimento (XXVII), castigo (XXX) e casamento (XXXI). }\end{array}$ \\
\hline Protagonista & Partida (XI) e reação do herói (XIII). \\
\hline Auxiliar & $\begin{array}{l}\text { Deslocamento (XV), reparação do dano (XIX), salvamento (XXII), } \\
\text { realização (XXVI) e transfiguração (XXIX). }\end{array}$ \\
\hline Mandante & Mediação (IX) \\
\hline Doador & Primeira função do doador (XII) e recepção do meio mágico (XIV) \\
\hline
\end{tabular}

Quadro 3: Distribuição das funções em esferas de ação

Fonte: Propp (Ibid.: 77-78)

\section{Raízes históricas do conto de magia}

Em As raízes históricas do conto maravilhoso, Propp (2002) estabelece as origens do conto de magia como gênero do discurso, levantando seu regimento e sua historicidade, em um olhar que contempla aspectos estruturais e contextuais. Esclarece o autor: "desejamos pesquisar a que fenômenos (e não a quais acontecimentos) do passado histórico corresponde o conto russo e em que medida esse passado histórico efetivamente o condiciona e motiva" (Ibid.: 2). A pesquisa foi desenvolvida a partir da sociologia e do marxismo em voga na Rússia, aplicados ao folclore - caudaloso substrato cultural constituído de valores, ritos, mitos, hábitos, crenças e saberes que emergem espontaneamente no seio social. O folclore é um pensamento coletivo fundado em resquícios temporais mantidos em meio a processos lentos de ressignificação. A leitura permitiu que Propp (Ibid.) indicasse que determinações atingiam, direta e indiretamente, o conto de magia, em operações de reflexão e/ou condicionamento.

O distanciamento preliminar, representado pelo afastamento, simboliza as atividades primitivas, sejam elas guerrear, trabalhar, viajar, vender, caçar, ou os falecimentos. Os contratos propostos às personagens, condensados na função proibição ou proposta, provém de mecanismos de defesa e de supervisão empregados pela nobreza 
e pela realeza no período feudal. São medidas cautelares promovidas quando se há ciência da negatividade no contexto. Protege-se, dessa forma, um símbolo coletivo. O extremo da sua aplicação gera o aprisionamento dos membros, detendo-os em um espaço. Costumes, rituais e crenças também podem levar a esta ação.

$\mathrm{O}$ antagonista sequestra ou provoca reações que culminam em banimento ou partida do herói, significado representado pela função homônima. Rivalidades podem levar ao exílio da personagem na mata. As transições espaciais no conto de magia são pontuais. Não há eventos no transcurso. Outros gêneros que surgem a posteriori se debruçam sobre a esfera espacial, desenvolvendo-a.

O processo de doação do auxiliar mágico, que compreende primeira função do doador, reação do herói e recepção do meio mágico, consiste em atestar a capacidade do iniciado a partir de uma prova de risco, sinalizando a mudança de estágio. É um processo severo de autoconhecimento e sobrevivência, que premia a natureza virtuosa do herói. Essa passagem manifesta sentidos fúnebres pelo cerramento da etapa. Há, ainda, a admissão em confrarias ou "casas masculinas" como ritual de passagem. O conto de magia explora essa localidade e seus bens valiosos. O objeto mágico pode estar relacionado a essa premissa.

A doação do objeto marca a transformação do herói fragilizado pelo dano para o herói fortalecido. $\mathrm{O}$ auxiliar mágico é uma qualidade ou potencialidade resolutiva do conflito. $\mathrm{O}$ objeto da transmissão confunde-se com o transmissor. $\mathrm{O}$ ocultismo está no entorno de ambos e estes são comumente associados.

O rito de iniciação compreendia a transmissão, ao jovem, do poder mágico sobre os animais. Mas os paralelos históricos que estabelecemos com certas modalidades de auxiliares não nos levaram ao rito de iniciação. Levaram-nos ao xamanismo, ao culto dos ancestrais, às concepções do além. Quando o rito caiu em desuso, a figura do auxiliar nem por isso desapareceu: começou a evoluir em função do desenvolvimento social e econômico, chegando aos anjos da guarda e santos da Igreja cristã. (Ibid.: 219-220)

A chegada incógnita é consequência do rito que marca o recomeço. Os esquecimentos são frutos da longa temporalidade. As tarefas difíceis carregam o mesmo sentido da doação do auxiliar mágico: a iniciação. Contudo, esse processo leva especificamente a contração da relação conjugal e, portanto, é um fenômeno pré-nupcial. A dificuldade e hostilidade manifestada na execução são comuns. A marcação do herói representa o seu ingresso na comunidade e antecede o matrimônio.

\section{Análise morfológica do núcleo de Cadinho na primeira fase}

A título de ilustração e pela sua curta extensão, são apresentadas as ações principais do núcleo de Cadinho na primeira fase da telenovela, compreendendo os sete primeiros capítulos. No quarto, Verônica abre as cortinas: "acorda, Cadinho. Chegou o grande dia" (AVENIDA BRASIL, 2012: c1 v6) ${ }^{5}$. Na cena seguinte, que contempla o café da manhã da família, Verônica revela o motivo da excitação: "tem que pedir alto pela corretora [...] amor, vinte milhões" (Ibid.). As cenas que se sucedem apresentam Cadinho despedindo-se de Verônica na sala, saindo do prédio, entrando no carro, conversando com o motorista e chegando na casa de Noêmia, a outra esposa. Na leitura de Propp (2010), o trecho contém os elementos que constituem a abertura da história ou situação inicial, responsável pela apresentação de personagens e suas relações. A monogamia como norma social deve ser resgatada e indicada com proibição ou proposta, contrato pré-estabelecido a ser cumprido. Ao manter dois casamentos secretamente, Cadinho rompe com essa diretriz - sua transgressão. A venda da corretora manifesta o sentido de carência a ser suprida, função que gera um percurso de reparação ou de realização.

No escritório, o bígamo assiste ao jogo da final do Campeonato Carioca enquanto aguarda a chegada dos executivos. Ao ingressarem em sua sala, inicia-se a reunião. 
Cadinho permanece assistindo à partida, o que gera a interrupção da ação dramática. Na leitura de Propp (Ibid.), o fragmento contém a tentativa de supressão da carência de Cadinho com a venda da corretora. A negociação é compreendida como combate, a ação direta que possibilita superar o dano ou carência. Provas e obstáculos integram esse processo.

No escritório, os executivos oferecem o valor inicialmente desejado: vinte milhões. Contudo, o bígamo recusa: "quarenta milhões. Nenhum centavo a menos" (AVENIDA BRASIL, 2012: c1 v13). Eles aceitam sua proposta: "é bem mais do que vale. Mas pra nós interessa. Negócio fechado" (Ibid.). Na leitura de Propp (2010), o evento mostra a vitória de Cadinho no combate, função que indica a sanção acerca da transação comercial e gera a reparação da carência.

Na festa, o bígamo pede: "Jimmy, vem cá. Liga pra minha mulher e fala que vou encontrar com ela em meia hora no Gino e Gino [...] a Verônica, lógico" (AVENIDA BRASIL, 2012: c1 v18). Na saída, Jimmy pede um bônus pela sua participação na venda e Cadinho recusa. Então ele articula o encontro de Cadinho com as duas esposas. Primeiramente, pede para que a secretária telefone para Noêmia e, depois, telefona para Verônica. Na leitura de Propp (2010), Jimmy manifesta a ardilosidade ao utilizar a informação da transgressão de Cadinho para promover o dano pela recusa da bonificação. A ardilosidade induz a personagem à ação que cause o dano, por meio do dado conquistado ou fornecido pela vítima, a informação. Nesse caso, Jimmy tem a informação da transgressão de Cadinho. O convite para o encontrarem no restaurante deve ser considerado como proposta, a predisposição a realizar algum ato.

Na entrada, Verônica e Noêmia chegam em seus carros e são recepcionadas pelo manobrista. O bígamo chega em seguida. Na entrada, ele é avisado: "pelo jeito o senhor está sendo esperado, seu Cadinho" (AVENIDA BRASIL, 2012: c1 v21). Cadinho vê as esposas sentadas em mesas próximas. Interrompe-se a ação dramática sem se demonstrar a reação do bígamo. Na leitura de Propp (2010), a cena revela a cumplicidade de Cadinho ao confiar no assessor. Essa função é instaurada quando a ardilosidade é eficaz.

Ao ver suas esposas, Cadinho coloca algumas cédulas de dinheiro no bolso do recepcionista: "pra todos os efeitos eu nunca estive aqui, entendeu? Eu vou sair por aquela porta, desaparecer. Se dona Noêmia ou dona Verônica perguntarem, eu nunca estive aqui" (AVENIDA BRASIL, 2012: c2 v5). Contudo, Cadinho é reconhecido por Mota que o chama. O bígamo acompanha o conhecido até a mesa. Diversas situações os colocam em evidência por ser aniversário da esposa de Mota, e Cadinho apavora-se. Seu comportamento gera estranhamentos e Mota expulsa-o. Ele vai embora sem ser notado por Noêmia ou Verônica. O fragmento apresenta, também, o encontro das esposas no banheiro. Na leitura de Propp (2010), Cadinho transgride a proposta da comemoração da venda da corretora com Verônica e Noêmia ao fugir, culminando no dano. O convite configura-se como proposta, e o seu descumprimento, como transgressão. As consequências são compreendidas como danos, que subtraem a harmonia da situação inicial.

No bar, Alexia conversa com o médico pelo telefone: “ah, doutor Jacob. Hoje é impossível voltar pra casa. A minha vidente me disse que hoje a noite eu ia sair e ia encontrar o reprodutor ideal, o pai do meu filho, isso. Ela disse que hoje a noite eu ia engravidar." (AVENIDA BRASIL, 2012: c2 v10). Cadinho chega cabisbaixo ao bar. Após desligar o celular, oferecer uma bebida e questioná-lo sobre doenças congênitas, a moça seduz o bígamo. Na leitura de Propp (2010), é apresentada a situação inicial de Alexia, com o desejo de engravidar, a carência. A primeira função apresenta a personagem, enquanto a segunda apresenta o desejo ou problema a ser sanado.

O bígamo tem uma noite intensa com a nova conquista amorosa. Ao amanhecer, Alexia dispensa-o. Na saída, Cadinho preocupa-se com a ausência de preservativo na relação e Alexia mente, afirmando que toma pílula. Cadinho vai embora e Alexia suplica: "ai, meu São Geraldo. Minha Santa Sara, pelo amor de Deus, faz nascer um bebê aqui nessa barriga" (AVENIDA BRASIL, 2012: c2 v11). Na leitura de Propp (2010), a tentativa de engravidar de Alexia carrega o sentido da função combate, a ação direta que suprirá a carência. Destaca-se, ainda, a transgressão de Alexia ao 
mentir sobre uso de pílula, sua ardilosidade ao induzir Cadinho a acreditar, o que gera sua cumplicidade. Ao relacionar-se com Alexia, Cadinho transgride a diretriz acerca da monogamia, enganando as esposas.

Na sala de jantar, Verônica toma seu café da manhã. A empregada questiona se pode tirar o prato do chefe da mesa. Ela responde: "amor, o prato, a cadeira, as roupas do armário, pode tirar tudo. Vou entregar pro primeiro carroceiro que aparecer na frente" (AVENIDA BRASIL, 2012: c4 v10). Sua raiva passa com os presentes enviados pelo marido: vestidos e um carro. Na leitura de Propp (2010), há a mediação, com a revelação do dano causado por Cadinho. Seu encontro com Verônica é vislumbrado como combate, uma ação direta que possibilita suprir o dano, ocasionado pela ausência no restaurante. Com os presentes, Cadinho reconquista a esposa - a vitória ou sanção positiva nesse confronto -, e gera a reparação do dano.

Noêmia entra na sala da casa irritada: "é o cúmulo. É inaceitável. Nem quando eu tinha dezoito anos eu namorava eu não fica plantada no restaurante esperando alguém" (AVENIDA BRASIL, 2012: c4 v11). A empregada avisa que Cadinho chegou em uma ambulância. No jardim, o enfermeiro explica: "dona Noêmia, foi acidente de carro. Foram muitas contusões" (Ibid.). Noêmia sente-se culpada: "você aqui todo machucado e eu lá dentro com raiva" (Ibid.). Com a saída de Noêmia, a farsa é desmontada. Na leitura de Propp (2010), há a mediação, com a revelação do dano causado por Cadinho. Seu encontro com Noêmia é vislumbrado como combate, uma ação direta que possibilita suprir o dano, ocasionado pela ausência no restaurante. Com a encenação, Cadinho reconquista a esposa - a vitória ou sanção positiva neste confronto -, e gera a reparação do dano.

Na corretora, o bígamo articula como ocorrerá sua passagem do ano: "pra minha sorte a Noêmia gosta sempre de passar o réveillon sozinha, meditando em um templo budista lá no Nepal. Eu vou levar a Verônica pra um resortezinho nas Maldivas" (AVENIDA BRASIL, 2012: c4 v15). Pelo telefone, Noêmia desconsidera a viagem: "que Nepal, Cadinho? Você não tem lido os jornais? Vai ter bug do milênio [...] Esse réveillon quero passar aqui no Rio" (Ibid.). Cadinho tenta convencer Verônica a não viajar: "Amor, cê não tem lido os jornais não? Vai ter o bug do milênio [...] a gente aluga, assim, uma suíte presidencial num hotel de luxo, chama os amigos, vê os fogos lá de cima, hein?" (Ibid.). Ao finalizar as ligações, Cadinho pede que Jimmy planeje as festas. Na leitura de Propp (2010), a ardilosidade e a cumplicidade são manifestadas por Cadinho ao lidar com as esposas. A primeira função induz a personagem à ação danosa, enquanto a segunda indica sua eficácia.

No portão, o bígamo interfona para Alexia, que o dispensa. Ele a segue e depara-se com a moça entrando em um estabelecimento para grávidas. Cadinho questiona-a sobre a gravidez, mas ela nega. Cadinho insiste: "eu só quero que, se por acaso você estiver grávida de mim, você precisaria saber de uma doença genética, hereditária da minha família" (Ibid.: c4 v16). Alexia desespera-se, e ele confirma sua suspeita. Na leitura de Propp (2010), a ardilosidade é manifestada por Cadinho ao mentir sobre doenças congênitas. Alexia acredita nele, indicativo de cumplicidade. A primeira função induz a personagem à ação danosa, enquanto a segunda indica sua eficácia. Com sua reação, Cadinho recebe a informação da transgressão de Alexia - a mentira sobre uso de pílula. A gravidez marca a reparação da carência de Alexia e tem o efeito do dano na situação de Cadinho, por transformá-la. Ao relacionar-se com Alexia, ele transgride a diretriz acerca da monogamia, enganando as esposas.

Enquanto arruma o quarto do bebê, a futura mãe é surpreendida pelo bígamo. Após o estranhamento, eles transam. Cadinho pede Alexia em namoro e ela promete pensar. Mantém-se a projeção em torno da gravidez como gancho narrativo. Na leitura de Propp (2010), a ardilosidade e a cumplicidade são manifestadas por Cadinho ao mentir sobre sua situação amorosa. A primeira função induz a personagem à ação danosa, enquanto a segunda indica sua eficácia. Ao relacionar-se com Alexia, Cadinho transgride a diretriz acerca da monogamia, enganando suas esposas.

Verônica e Noêmia dão festas de réveillon no mesmo hotel. Ao ser convidada por Verônica, Alexia descobre que Cadinho é casado. Ela segue-o, descobrindo a 
bigamia. Alexia ameaça desmascará-lo. Na leitura de Propp (2010), a descoberta da bigamia emerge como dano e mediação para Alexia, que entra em combate com Cadinho. O dano subtrai a harmonia da situação inicial. Já a mediação consiste na tomada de consciência do dano e da situação transformada. Por fim, o combate é uma ação direta que possibilita superar o dano.

O bígamo arrasta Alexia para a praia e tenta explicar-se: "Alexia, me escuta. Eu amo vocês três. Eu amo todos os meus filhos. Os que já tenho. Os que vou ter. Eu sempre cuidei de todo mundo" (AVENIDA BRASIL, 2012: c6 v19). Alexia esbraveja: "para, para, para. Cê pensa que cê mora onde? Pelo amor de Deus, cê pensa que tá morando num harém?" (Ibid.). Ao final, Cadinho promete: "fica tranquila. Vai dar tudo certo. Eu vou cuidar de você, viu? Eu vou te fazer muito feliz" (Ibid.). Cadinho beija Alexia, que dá um tapa na cara dele e o beija. Na leitura de Propp (2010), Cadinho tem a vitória ou sanção positiva no combate com Alexia e repara o dano da descoberta da bigamia. No Quadro 4 é demonstrada a análise da primeira fase da novela de forma simplificada.

\begin{tabular}{|c|c|c|c|c|c|c|c|}
\hline $\mathrm{v} / \mathrm{c}$ & Capítulo 1 & Capítulo 2 & Capítulo 3 & Capítulo 4 & Capítulo 5 & Capítulo 6 & Capítulo 7 \\
\hline 1 & $\begin{array}{c}1 . \\
\text { Dano I } \\
2 . \\
\text { Carência I }\end{array}$ & $\begin{array}{c}7 . \\
\text { Início da reação } \\
\text { ao dano IV }\end{array}$ & $\begin{array}{c}7 . \\
\text { Informação III } \\
\text { sobre a } \\
\text { transgressão II }\end{array}$ & $\begin{array}{c}8 . \\
\text { Início da reação } \\
\text { ao dano IX }\end{array}$ & $\begin{array}{c}7 . \\
\text { Mediação do } \\
\text { dano IV }\end{array}$ & $\begin{array}{c}13 . \\
\text { Dano XIII }\end{array}$ & $\begin{array}{c}15 . \\
\text { Transgressão IX }\end{array}$ \\
\hline 2 & $\begin{array}{c}3 . \\
\text { Carência II }\end{array}$ & $\begin{array}{c}6 . \\
\text { Combate para } \\
\text { dano III }\end{array}$ & \begin{tabular}{|c|}
7. \\
Início da reação \\
ao dano IV \\
\end{tabular} & $\begin{array}{l}\text { 7.ंidade II } \\
\text { Cumplicidansgressão VII } \\
\end{array}$ & $\begin{array}{c}10 . \\
\text { Dano X }\end{array}$ & $\begin{array}{c}12 . \\
\text { Ardilosidade VI } \\
\text { Cumplicidade VI }\end{array}$ & $\begin{array}{c}12 . \\
\text { Ardilosidade IX }\end{array}$ \\
\hline 3 & $\begin{array}{c}1 . \\
\begin{array}{c}\text { Reparação } \\
\text { do dano I }\end{array} \\
4 . \\
\text { Proposta I }\end{array}$ & $\begin{array}{c}7 . \\
\text { Início da reação } \\
\text { ao dano IV }\end{array}$ & \begin{tabular}{|c|}
8 \\
Transgressão IV \\
8. \\
Transgressão V \\
Informação IV \\
sobre a \\
transgressão V
\end{tabular} & $\begin{array}{c}8 . \\
\text { Início da reação } \\
\text { ao dano IX }\end{array}$ & $\begin{array}{c}8 . \\
\text { Casamento }\end{array}$ & $\begin{array}{c}13 . \\
\text { Dano XIV }\end{array}$ & $\begin{array}{c}15 . \\
\text { Informação da } \\
\text { transgressão IX }\end{array}$ \\
\hline 4 & $\begin{array}{c}5 . \\
\text { Transgressão I e } \\
\text { informação I da } \\
\text { transgressão I }\end{array}$ & $\begin{array}{c}6 . \\
\text { Combate para } \\
\text { dano III }\end{array}$ & $\begin{array}{c}8 . \\
\text { Dano VII }\end{array}$ & $\begin{array}{c}7 . \\
\text { Informação da } \\
\text { transgressão VII }\end{array}$ & $\begin{array}{c}8 . \\
\text { Casamento }\end{array}$ & $\begin{array}{c}12 . \\
\text { Ardilosidade VII } \\
\text { Cumplicidade VII }\end{array}$ & $\begin{array}{c}12 . \\
\text { Ardilosidade IX }\end{array}$ \\
\hline 5 & $\begin{array}{c}5 . \\
\text { Informação II da } \\
\text { transgressão I }\end{array}$ & & $\begin{array}{c}11 . \\
\text { Carência III }\end{array}$ & $\begin{array}{c}10 . \\
\text { Interrogatório } \\
\text { visando } \\
\text { transgressão VII }\end{array}$ & $\begin{array}{c}10 . \\
\text { Início da reação } \\
\text { ao dano X }\end{array}$ & $\begin{array}{c}13 . \\
\text { Início da reação } \\
\text { ao dano XIV }\end{array}$ & $\begin{array}{l}10 . \\
\text { Mediação do } \\
\text { dano X }\end{array}$ \\
\hline 6 & & $\begin{array}{c}7 . \\
\text { Início da reação } \\
\text { ao dano IV }\end{array}$ & $\begin{array}{c}8 . \\
\text { Dano VIII } \\
\text { proibição I }\end{array}$ & $\begin{array}{c}10 . \\
\text { Informação VI da } \\
\text { transgressão VII } \\
\text { Dano X }\end{array}$ & $\begin{array}{c}10 . \\
\text { Início da reação } \\
\text { ao dano X } \\
\text { Partida }\end{array}$ & $\begin{array}{c}8 . \\
\text { Dano XV }\end{array}$ & $\begin{array}{c}15 . \\
\text { Ardilosidade VII }\end{array}$ \\
\hline 7 & $\begin{array}{c}5 . \\
\text { Dano II } \\
\begin{array}{c}\text { Início da reação } \\
\text { ao dano II }\end{array} \\
6 . \\
\text { Dano III } \\
\text { Início da reação } \\
\text { ao dano III }\end{array}$ & $\begin{array}{c}6 . \\
\begin{array}{c}\text { Combate para } \\
\text { dano III }\end{array} \\
7 . \\
\text { Mediação do } \\
\text { dano IV }\end{array}$ & $\begin{array}{c}7 . \\
\text { Informação V }\end{array}$ & $\begin{array}{c}8 . \\
\text { Interrogatório I }\end{array}$ & $\begin{array}{l}7 . \\
\text { Reparação do } \\
\text { dano IV }\end{array}$ & $\begin{array}{l}13 . \\
\text { Reparação do } \\
\text { dano XIV }\end{array}$ & $\begin{array}{c}15 . \\
\text { Dano XIX }\end{array}$ \\
\hline 8 & $\begin{array}{c}5 . \\
\text { Início da reação } \\
\text { ao dano II }\end{array}$ & $\begin{array}{c}7 . \\
\text { Mediação } \\
\text { Dano IV }\end{array}$ & $\begin{array}{c}7 . \\
\text { Início da reação } \\
\text { ao dano IV } \\
\text { Proposta II }\end{array}$ & $\begin{array}{c}8 . \\
\text { Combate, vitória } \\
\text { e reparação do } \\
\text { dano IX }\end{array}$ & $\begin{array}{c}10 . \\
\text { Início da reação } \\
\text { ao dano X } \\
\text { Partida }\end{array}$ & $\begin{array}{c}12 . \\
\text { Ardilosidade VI } \\
\text { Cumplicidade VI }\end{array}$ & $\begin{array}{l}15 . \\
\text { Reparação do } \\
\text { dano XIX }\end{array}$ \\
\hline
\end{tabular}




\begin{tabular}{|c|c|c|c|c|c|c|c|}
\hline $\mathrm{v} / \mathrm{c}$ & Capítulo 1 & Capítulo 2 & Capítulo 3 & Capítulo 4 & Capítulo 5 & Capítulo 6 & Capítulo 7 \\
\hline 9 & $\begin{array}{c}2 . \\
\text { Combate da } \\
\text { carência I }\end{array}$ & $\begin{array}{c}7 . \\
\text { Mediação do } \\
\text { dano IV }\end{array}$ & $\begin{array}{c}8 . \\
\text { Transgressão VI }\end{array}$ & $\begin{array}{l}10 . \\
\text { Combate, vitória } \\
\text { e reparação do } \\
\text { dano X }\end{array}$ & & $\begin{array}{c}8 . \\
\text { Interrogatório II }\end{array}$ & $\begin{array}{c}15 . \\
\text { Reparação do } \\
\text { dano XIX }\end{array}$ \\
\hline 10 & $\begin{array}{c}2 . \\
\text { Combate da } \\
\text { carência I }\end{array}$ & & $\begin{array}{c}7 . \\
\text { Ardilosidade II }\end{array}$ & & $\begin{array}{c}8 . \\
\text { Casamento }\end{array}$ & $\begin{array}{c}8 . \\
\text { Informação VIII }\end{array}$ & $\begin{array}{c}12 . \\
\text { Dano XVIII }\end{array}$ \\
\hline 11 & $\begin{array}{c}6 . \\
\text { Início da reação } \\
\text { ao dano III }\end{array}$ & & $\begin{array}{c}8 . \\
\text { Dano IX } \\
\text { Início da reação } \\
\text { ao dano IX }\end{array}$ & & & $\begin{array}{c}12 . \\
\text { Ardilosidade VII } \\
\text { Cumplicidade VII } \\
\text { Dano XVI }\end{array}$ & $\begin{array}{c}16 . \\
\text { Carência VII }\end{array}$ \\
\hline 12 & $\begin{array}{c}2 . \\
\text { Combate da } \\
\text { carência I }\end{array}$ & 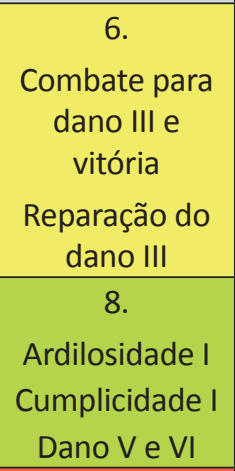 & $\begin{array}{c}7 . \\
\text { Ardilosidade II }\end{array}$ & $\begin{array}{c}11 . \\
\text { Reparação da } \\
\text { carência III }\end{array}$ & $\begin{array}{c}12 . \\
\text { Ardilosidade IV } \\
\text { Cumplicidade IV }\end{array}$ & $\begin{array}{c}12 . \\
\text { Mediação do } \\
\text { dano XVI }\end{array}$ & $\begin{array}{c}11 . \\
\text { Reparação da } \\
\text { carência III }\end{array}$ \\
\hline 13 & & $\begin{array}{c}7 . \\
\text { Início da reação } \\
\text { ao dano IV }\end{array}$ & $\begin{array}{c}8 . \\
\text { Início da reação } \\
\text { ao dano IX }\end{array}$ & $\begin{array}{c}13 . \\
\text { Carência IV }\end{array}$ & $\begin{array}{c}10 . \\
\text { Início da reação } \\
\text { ao dano XI e } \\
\text { Partida }\end{array}$ & $\begin{array}{c}14 . \\
\text { Dano XVII }\end{array}$ & $\begin{array}{c}16 . \\
\text { Ardilosidade X }\end{array}$ \\
\hline 14 & $\begin{array}{c}2 . \\
\text { Combate da } \\
\text { carência I }\end{array}$ & $\begin{array}{c}8 . \\
\begin{array}{c}\text { Mediação do } \\
\text { dano VI }\end{array}\end{array}$ & $\begin{array}{c}7 . \\
\text { Ardilosidade II }\end{array}$ & $\begin{array}{c}14 . \\
\text { Carência V } \\
\text { Informação }\end{array}$ & $\begin{array}{c}12 . \\
\text { Ardilosidade IV } \\
\text { Cumplicidade IV } \\
\text { Ardilosidade VI }\end{array}$ & $\begin{array}{l}10 . \\
\text { Mediação do } \\
\text { dano X }\end{array}$ & $\begin{array}{c}16 . \\
\text { Cumplicidade } \\
\text { Reparação de } \\
\text { carência VII }\end{array}$ \\
\hline 15 & $\begin{array}{c}5 . \\
\text { Deslocamento } \\
\text { Combate para } \\
\text { reparação do } \\
\text { dano II }\end{array}$ & $\begin{array}{c}7 . \\
\text { Início da reação } \\
\text { ao dano IV } \\
\text { Transgressão II }\end{array}$ & $\begin{array}{c}10 . \\
\text { Transgressão III }\end{array}$ & & $\begin{array}{c}12 . \\
\text { Ardilosidade V }\end{array}$ & $\begin{array}{c}15 . \\
\text { Carência VI }\end{array}$ & $\begin{array}{c}16 . \\
\text { Reparação de } \\
\text { carência VII }\end{array}$ \\
\hline 16 & \begin{tabular}{|c|}
5. \\
$\begin{array}{c}\text { Combate para } \\
\text { reparação do } \\
\text { dano Il e Vitória }\end{array}$ \\
6. \\
$\begin{array}{c}\text { Início da Reação } \\
\text { ao Dano III }\end{array}$ \\
\end{tabular} & $\begin{array}{c}7 . \\
\text { Início da reação } \\
\text { ao dano IV } \\
\text { Transgressão II }\end{array}$ & $\begin{array}{c}7 . \\
\text { Cumplicidade II }\end{array}$ & & $\begin{array}{c}8 . \\
\text { Casamento }\end{array}$ & & $\begin{array}{c}16 . \\
\text { Reparação do } \\
\text { dano XIX }\end{array}$ \\
\hline 17 & $\begin{array}{c}2 . \\
\text { Combate, vitória } \\
\text { e reparação da } \\
\text { carência I }\end{array}$ & $\begin{array}{c}7 . \\
\text { Início da reação } \\
\text { ao dano IV } \\
\text { Transgressão II }\end{array}$ & & $\begin{array}{c}10 . \\
\text { Ardilosidade III } \\
\text { Cumplicidade III } \\
\text { Transgressão VIII }\end{array}$ & $\begin{array}{c}12 . \\
\text { Cumplicidade V }\end{array}$ & $\begin{array}{c}12 . \\
\text { Ardilosidade VII }\end{array}$ & \\
\hline 18 & & $\begin{array}{c}8 . \\
\text { Início da reação } \\
\text { ao dano VI }\end{array}$ & & $\begin{array}{c}10 . \\
\text { Informação VII da } \\
\text { transgressão VIII }\end{array}$ & $\begin{array}{c}8 . \\
\text { Casamento }\end{array}$ & $\begin{array}{c}12 . \\
\text { Cumplicidade VII } \\
\text { Dano XVIII }\end{array}$ & \\
\hline 19 & $\begin{array}{c}6 . \\
\text { Início da reação } \\
\text { ao dano III }\end{array}$ & $\begin{array}{c}7 . \\
\text { Início da reação } \\
\text { ao dano IV } \\
\text { Transgressão II }\end{array}$ & & $\begin{array}{l}10 . \\
\text { Ardilosidade III } \\
\text { Cumplicidade III }\end{array}$ & $\begin{array}{c}13 . \\
\text { Dano XII }\end{array}$ & & \\
\hline 20 & $\begin{array}{c}2 . \\
\text { Reparação da } \\
\text { carência I }\end{array}$ & $\begin{array}{c}8 . \\
\text { Início da reação } \\
\text { ao dano VI }\end{array}$ & & $\begin{array}{c}10 . \\
\text { Informação VII da } \\
\text { transgressão VIII }\end{array}$ & & $\begin{array}{c}10 . \\
\text { Mediação do } \\
\text { dano X }\end{array}$ & \\
\hline
\end{tabular}




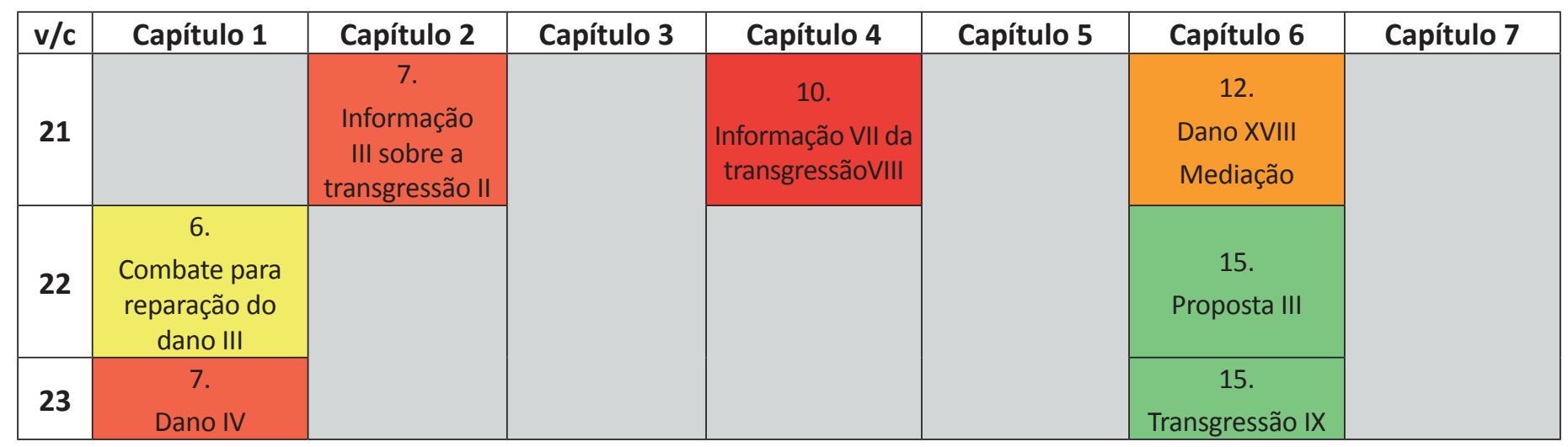

Quadro 4: Funções na primeira fase de Avenida Brasil

Fonte: Cazani Júnior (2016)

\begin{tabular}{|c|l|}
\hline 1 & \multicolumn{1}{|c|}{ Assunto } \\
\hline 1 & Anúncio de casamento \\
\hline 2 & Campeonato Carioca \\
\hline 3 & Carminha e Rita \\
\hline 4 & Casamento de Tufão e Monalisa \\
\hline 5 & Genésio descobre o golpe \\
\hline 6 & O golpe fracassa \\
\hline 7 & Morte de Genésio \\
\hline 8 & Rita no lixão \\
\hline 10 & Núcleo Cadinho \\
\hline 10 & Monalisa e Tufão \\
\hline 11 & Salão de cabeleireiro \\
\hline 12 & Casamento de Carminha e Tufão \\
\hline 13 & Acidente de ônibus \\
\hline 14 & Adauto e o dinheiro \\
\hline 15 & Rita e Tufão \\
\hline 16 & Adoção de Batata \\
\hline
\end{tabular}

Quadro 5: Índice de referência da organização na telenovela Fonte: Cazani Júnior (2016)

Para a compreensão dos Quadros 4 e 5, resgatam-se as principais ações das análises:

- Dano I: Monalisa acredita que Tufão casará com outra.

- Dano II: Genésio comprova que Carminha tramou um golpe contra ele.

- Dano III: Os motoqueiros encontram papéis na bolsa no lugar de dinheiro.

- Dano IV: Tufão atropela e mata Genésio.

- Dano V: Rita perde o dinheiro.

- Dano VI: Rita é abandonada no lixão.

- Dano VII: Rita se estranha com Nilo.

- Dano VIII: Nilo descobre dinheiro com Jéssica e a impede de comer.

- Dano IX: Rita enfrenta Nilo e fica desabrigada.

- Dano X: Tufão termina o namoro com Monalisa.

- Dano XI: Monalisa termina com Tufão.

- Dano XII: Monalisa e passageiros sofrem acidente de ônibus.

- Dano XIII: Morre a mãe de Iram.

- Dano XIV: Monalisa perde o bebê.

- Dano XV: Nilo acaba com a festa de casamento de Batata e Rita.

- Dano XVI: Carminha rompe com Tufão.

- Dano XVII: Adauto distribui seu dinheiro para populares.

- Dano XVIII: Tufão pede Carminha em casamento e cai no golpe.

- Dano XIX: Lucinda avisa que Rita terá que ir embora do lixão.

- Carência I: Tufão deseja vencer a final do Campeonato Carioca.

- Carência II: Conflito entre Carminha e Rita.

- Carência III: Monalisa deseja abrir seu salão. 
- Carência IV: Monalisa está grávida.

- Carência V: Carminha está grávida.

- Carência VI: Ivana é solteirona e quer namorar.

- Carência VII: Carminha rejeita a filha.

- Combate para carência I: Jogo da final do Campeonato Carioca.

- Combate Dano I: Tufão esclarece o mal-entendido e pede Monalisa em casamento.

- Combate Dano II: Genésio confronta Carminha, tenta prendê-la e é ferido.

- Combate Dano III: Carminha retorna para casa para procurar o dinheiro.

- Informação I da transgressão I: Rita descobre o plano da madrasta.

- Informação II da transgressão I: Rita avisa seu pai do plano de Carminha.

- Informação III da transgressão II: Carminha descobre que Tufão atropelou Genésio.

- Informação IV da transgressão V: Nilo descobre que Rita não está coletando objetos.

- Informação V: Max levanta informações sobre Tufão e Monalisa.

- Informação VI da transgressão VII: Carminha conta para Max que transou com Tufão.

- Informação VII da transgressão VIII: Monalisa descobre que Tufão saiu da festa.

- Informação VIII: Rita relata sua história.

- Informação XI da transgressão IX: Lucinda descobre que Rita foi procurar Tufão.

- Início da reação ao dano I: Monalisa confronta Tufão.

- Início da reação ao dano II: Genésio esconde o dinheiro e mantém a farsa do assalto.

- Início da reação ao dano III: Os motoqueiros acionam Max.

- Segunda reação ao dano III: Max aciona Carminha.

- Terceira reação ao dano IIII: Carminha foge até a casa de Max.

- Início da reação ao dano IV: Tufão aciona o resgate.

- Transgressão I: Carminha planeja um golpe contra Genésio.

- Transgressão II: Tufão mente sobre conhecer Genésio.

- Transgressão III: Tufão deixa Monalisa esperando no hotel.

- Transgressão IV: Jéssica desvia dinheiro da coleta do lixo.

- Transgressão V: Rita deixa de coletar objetos e passa a brincar com Batata.

- Transgressão VI: Rita ajuda Jéssica.

- Transgressão VII: Tufão transa com Carminha.

- Transgressão VIII: Tufão sai da festa de noivado sem avisar.

- Transgressão IX: Rita decide procurar Tufão.

- Proposta I: Tufão pede Monalisa em casamento.

- Proposta II: Tufão promete regressar rápido ao hotel.

- Proibição I: Nilo proíbe que as crianças ajudem Jéssica.

- Proposta III: Lucinda pede que Rita não procure vingança.

- Interrogatório I: Lucinda questiona Batata sobre o paradeiro de Rita.

- Interrogatório II: Lucinda questiona Rita sobre sua história.

- Ardilosidade I: Carminha finge que irá embora para encontrar o dinheiro.

- Ardilosidade II: Carminha alimenta a culpa de Tufão para seduzi-lo.

- Ardilosidade III: Carminha finge que irá se matar.

- Ardilosidade IV: Muricy convida Carminha para ir a Cabo Frio.

- Ardilosidade V: Muricy tenta convencer Tufão de ir a Cabo Frio.

- Ardilosidade VI: Carminha arma um plano com o paparazzo.

- Ardilosidade VII: Carminha seduz Tufão.

- Ardilosidade VIII: Rita tenta desmascarar Tufão.

- Ardilosidade IX: Carminha pede para Max conquistar Ivana.

- Ardilosidade X: Carminha quer adotar Batata.

- Cumplicidade I: Rita caí no golpe planejado por Carminha.

- Cumplicidade II: Carminha seduz Tufão.

- Cumplicidade III: Tufão acredita na tentativa de suicídio de Carminha.

- Cumplicidade IV: Carminha aceita o convite de Muricy.

- Cumplicidade V: Tufão aceita a proposta de Muricy.

- Cumplicidade VI: Paparazzo fotografa Carminha e Tufão juntos.

- Cumplicidade VII: Tufão é seduzido por Carminha. 


\section{Considerações finais}

A análise formalista possibilitou levantar como foi criada a história de Avenida Brasil (2012). Seu enunciado é formado por múltiplas linhas narrativas que são desenroladas de modo desigual no decorrer dos capítulos. Diferentes estágios são encontrados em um mesmo trecho. Isso possibilita manter a expectativa da audiência que espera pela reparação de um dano enquanto vislumbra outro dano emergir. O reinício do encadeamento é contínuo.

Há muitos conflitos, que são representados pelas funções dano e carência. Para reiterá-los, emprega-se, intensivamente, a função mediação. Os danos são multidimensionais: atingem e geram vários desdobramentos. O arranjo clássico proppiano estabelece a instauração do dano com a sua mediação. Em Avenida Brasil (2012), a narrativa expõe adversidades antes mesmo da sua concretização, podendo, de fato, não acontecer. Um exemplo disso é o golpe tramado por Carminha, logo no primeiro capítulo. O público e Genésio descobrem sua ocorrência e mantêm-no em curso como início da reação. Os encadeamentos são curtos e completam-se no mesmo capítulo: a adversidade é instaurada e reparada rapidamente, reiniciando o ciclo de forma contínua.

As funções que funcionam como gancho de final de capítulo induzem ou desestabilizam a história. Dano representa a emersão de conflito. Informação, transgressão e cumplicidade promovem sua ocorrência, estando no seu limiar. Dessa forma, a articulação para criação de adversidades e a sua própria instauração são utilizadas no recurso e alimentam a história. Um eterno recomeço move a narrativa, fazendo-a não se fechar.

\section{Referências}

AVENIDA Brasil. Roteiro: João Emanuel Carneiro. Direção: Gustavo Fernandez, Joana Jabace, Paulo Silvestrini, Thiago Teitelroit e Andre Camara. Rio de Janeiro: Globo, 2012. 179 capítulos, color. Disponível em: <https://goo.gl/YR1EL5>. Acesso em: 11 fev. 2016.

CAZANI JÚNIOR, L. E. Da veiculação em fluxo contínuo para a disponibilização: o gancho na produção de sentido da telenovela Avenida Brasil. 2016. 190 f. Dissertação (Mestrado em Comunicação) - Faculdade de Arquitetura, Artes e Comunicação, Universidade Estadual Paulista "Júlio de Mesquita Filho", Bauru, 2016. Disponível em: <https://goo.gl/r91xXW>. Acesso em: 26 jul. 2017.

PROPP, V. As raízes históricas do conto maravilhoso. Tradução Rosemary Costhek Abílio, Paulo Bezerra. São Paulo: Martins Fontes, 2002.

Morfologia do conto maravilhoso. Tradução Jasna Paravich Sarhan. Rio de Janeiro: Forense Universitária, 2010. 